\title{
Liderança e Inteligência Emocional: Sentidos do exercício da liderança por mulheres do Assentamento Marrecas, SJ-PI
}

\author{
Leadership and Emotional Intelligence: Meanings of the exercise of leadership by women from the \\ Marrecas Settlement, SJ-PI \\ Liderazgo e Inteligencia Emocional: Significados del ejercicio del liderazgo por parte de mujeres \\ del Asentamiento Marrecas, SJ-PI
}

Recebido: 28/05/2021 | Revisado: 06/06/2021 | Aceito: 22/06/2021 | Publicado: 05/07/2021

\author{
Ana Rayla de Araújo Silva \\ ORCID: https://orcid.org/0000-0002-1476-148X \\ Universidade Federal do Piauí, Brasil \\ E-mail: anaraylasilva@gmail.com \\ Rayana Taís da Silva \\ ORCID: https://orcid.org/0000-0003-3462-9723 \\ Universidade Federal do Piauí, Brasil \\ E-mail: rayanearaujo7a1@gmail.com \\ Flávia Lorenne Sampaio Barbosa \\ ORCID: https://orcid.org/0000-0002-4804-9538 \\ Universidade Federal do Piauí, Brasil \\ E-mail: flsbarbosa@ufpi.edu.br \\ Marceane Barros Lourenço \\ ORCID: https://orcid.org/0000-0003-2364-248X \\ Universidade Federal do Piauí, Brasil \\ E-mail: ceane_barros@hotmail.com
}

\begin{abstract}
Resumo
A liderança faz parte das nossas vidas de forma cotidiana, e a inteligência emocional vem ganhando destaque nos estudos. Neste sentido este trabalho objetivou compreender a relação da liderança e da inteligência emocional na formação das líderes rurais femininas do Assentamento Marrecas, em São João do Piauí-PI. Para o alcance dos objetivos propostos neste trabalho, realizou-se uma pesquisa qualitativa-descritiva, a coleta de dados foi feita por meio da realização de entrevista semiestruturada, realizada com 5 (cinco) mulheres que exercem a liderança dentro do assentamento. Como resultado, concluiu-se que traços da liderança transformacional, situacional (ou contingencial) e comportamental; e aspectos da inteligência emocional como, empatia, autocontrole, motivação e autoconhecimento estão no seio da formação da liderança feminina das entrevistadas. Por certo, essas características estão promovendo, favoravelmente, a construção e formação da liderança feminina dessa comunidade, mesmo diante da própria insegurança, do medo, da dificuldade de articulação e comunicação, na qual, por serem mulheres, ainda são vistas com "maus olhares". Além das dificuldades em conciliar as funções, enquanto mulher, do trabalho e do lar e serem julgadas por terem que deixar a casa e irem trabalhar fora.
\end{abstract}

Palavras-chave: Liderança feminina; Inteligência emocional feminina; Comunidade rural.

\begin{abstract}
Leadership is part of our daily lives, and emotional intelligence has been gaining prominence in studies. In this sense, this work aimed to understand the relationship of leadership and emotional intelligence in the formation of rural female leaders of the Marrecas Settlement, in São João do Piauí-PI. In order to achieve the objectives proposed in this work, a qualitative-descriptive research was carried out, data collection was carried out by means of a semi-structured interview, carried out with 5 (five) women who exercise leadership within the settlement. As a result, it was concluded that traits of transformational, situational (or contingency) and behavioral leadership; and aspects of emotional intelligence such as empathy, self-control, motivation and self-knowledge are at the heart of the interviewees' female leadership training. Certainly, these characteristics are favorably promoting the construction and formation of the female leadership of this community, even in the face of their own insecurity, fear, difficulty in articulation and communication, in which, because they are women, they are still seen with "bad looks." In addition to the difficulties in reconciling the functions, as a woman, of work and home and being judged for having to leave the house and go to work outside.
\end{abstract}

Keywords: Women's leadership; Women's emotional intelligence; Rural community. 


\section{Resumen}

El liderazgo es parte de nuestra vida diaria y la inteligencia emocional ha ido ganando protagonismo en los estudios. En este sentido, este trabajo tuvo como objetivo comprender la relación del liderazgo y la inteligencia emocional en la formación de mujeres líderes rurales del Asentamiento Marrecas, en São João do Piauí-PI. Para lograr los objetivos propuestos en este trabajo, se realizó una investigación cualitativo-descriptiva, la recolección de datos se realizó mediante una entrevista semiestructurada, realizada con 5 (cinco) mujeres que ejercen el liderazgo dentro del asentamiento. Como resultado, se concluyó que los rasgos de liderazgo transformacional, situacional (o contingente) y conductual; y aspectos de la inteligencia emocional, como la empatía, el autocontrol, la motivación y el autoconocimiento, están en el centro de la formación del liderazgo femenino de las entrevistadas. Ciertamente, estas características están impulsando favorablemente la construcción y formación del liderazgo femenino de esta comunidad, incluso ante la propia inseguridad, el miedo, la dificultad de articulación y comunicación, en la que, por ser mujeres, todavía se las ve con "mal aspecto." Además de las dificultades para conciliar las funciones, como mujer, del trabajo y del hogar y ser juzgada por tener que salir de casa e ir a trabajar fuera.

Palabras clave: Liderazgo femenino; Inteligencia emocional de las mujeres; Comunidad rural.

\section{Introdução}

"Prá mudar a sociedade do jeito que a gente quer. Participando sem medo de ser Mulher" (Pinto, 2015)

A liderança faz parte das nossas vidas de forma cotidiana, permeando desde o meio profissional até o ambiente pessoal. Para Bateman e Snell (1998) a liderança é o ato de influenciar um grupo, de maneira positiva, para alcançar seus objetivos e metas. Seguindo esse pensamento, faz-se necessário que se tenham lideres capacitados, seja nas instituições, nas organizações, ou no meio acadêmico, que sirvam de modelo a ser seguido. Desse modo, líderes eficazes apresentam semelhanças, pois além de possuírem habilidades técnicas, tem-se também um elevado grau de inteligência emocional (Goleman, 1998).

A inteligência emocional vem ganhando destaque nos estudos, e se apresenta como um aspecto singular para ascensão da liderança, sendo ela feminina ou masculina (Tomazela, 2018). Sendo que, para um determinado indivíduo, a inteligência emocional envolve competências emocionais e relacionais, contribuindo assim, para o êxito pessoal e profissional (Santos, 2011). Mayer e Salovey (1997) ressaltam que a inteligência emocional (IE) é a capacidade de o indivíduo perceber seus sentimentos e emoções e as dos outros, discriminá-los e, assim, empregar essa informação da melhor forma, guiando o próprio pensamento e ações.

Na busca por uma liderança e uma administração mais humanizada, a discussão a respeito de gêneros está cada vez mais presente na dinâmica organizacional (Tomazela, 2018). Nesse sentido, destaca-se que lideranças femininas que são focadas nas relações humanas e em habilidades sociais, demostram-se eficaz para as organizações (Latu et al, 2013).

Quanto ao diferencial que uma liderança feminina pode trazer, Teixeira (2001) ressalta características femininas que são essenciais para uma boa liderança, bem como, generosidade, harmonia, boa comunicação, capacidade de liderar de forma cooperativa, participativa, menos centrada em si mesma (líder), facilidade de negociação e resolução de problemas que baseiase na empatia e racionalidade.

Por certo, as mulheres lutam há muitos anos por uma equivalência de direitos sem que haja uma diferenciação baseada no gênero, podendo chegar a maiores cargos, ter o direito de ganhar os mesmos salários conforme cargos ex ercidos e ter o mesmo poder de voz (Rodrigues \& Silva, 2015). Como resultado dessas lutas, as mulheres chegam a lugares não imaginados nas organizações e na sociedade, mas mesmo com esse avanço, as mulheres enfrentam muitos desafios (Tomazela, 2018).

Dentre eles, pode-se ressaltar a atuação das mulheres no movimento sem terra (mst), no qual se diz que, mulheres e homens desempenham o mesmo protagonismo político, porém, a mulher, traz consigo características femininas, bem como postura de trabalhadora e que, por assim ser, é muito mais que uma tática para a resistência, é bem mais que filha, esposa ou mãe (Coletivo Nacional de Mulheres, 1998). 
Assim, a proposta desse estudo é refletir sobre o perfil de liderança e habilidades de inteligência emocional das líderes rurais femininas, no Assentamento Marrecas, localizado em São João do Piauí-PI. Como problema de pesquisa tem-se: como a liderança e a inteligência emocional promovem a formação das líderes rurais femininas do Assentamento Marrecas, em São João do Piauí-PI?

O objetivo geral da pesquisa é compreender como a liderança e a inteligência emocional promovem a formação das líderes rurais femininas do Assentamento Marrecas, em São João do Piauí-PI. Dessa feita, tem-se, especificadamente, identificar os perfis de liderança dessas mulheres; levantar as habilidades de inteligência emocional em suas condutas como líderes; e, por fim, identificar possíveis dificuldades na formação da liderança feminina dentro da comunidade em que atuam.

A presente pesquisa se justifica embasada em Tomazela (2018), pois mostra a importância de que estudos sejam realizados sobre a mulher em cargos de gestão, haja vista sua representatividade e posições diferenciadas nos negócios. Assim, contribuirá, socialmente, por buscar uma discussão dessa liderança feminina em comunidades de áreas rurais, evidenciando olhares nas ações dessas mulheres, nesse aspecto, é fundamental investigar como ocorre esse processo. Na área da gestão, promoverá incentivo para que mais mulheres se engajem nessa perspectiva e que possam se reconhecer com agentes de transformação para a comunidade em que vivem.

$\mathrm{Na}$ primeira seção, a presente introdução traz definições preliminares de liderança e inteligência emocional, bem como a relação entre liderança feminina e inteligência emocional e o escopo do trabalho de pesquisa. Na segunda seção, temos o referencial teórico onde são apresentadas a definição e as abordagens de liderança e também a inteligência emocional, conceituando e delimitando esse tema. A terceira seção aborda a metodologia usada para pesquisa. Essa reflexão será complementada por pesquisa de campo para avaliar a situação real das mulheres em posição de liderança.

\section{Fundamentação Teórica}

\subsection{Liderança}

Considerando as constantes transformações na atualidade, é notório o valor de um bom líder que seja capaz de lidar com as frequentes mudanças e incertezas, suportando ambiguidades, estimulando e orientando seus seguidores na busca de melhores resultados em um ambiente de desafios, garantindo o sucesso e a eficácia para a sociedade e organizações (Macedo et al, 2011). Logo, a liderança é vista como um processo de influência perante a um indivíduo ou determinado grupo, conduzindo assim ao alcance dos objetivos estabelecidos (Teixeira, 2001). Atualmente, as organizações procuram um líder que faça a diferença, pois não existe mais espaço para líderes centralizadores que simplesmente delegam tarefas (Tornani, 2011). Hunter (2006) ressalta que a liderança, na busca de atingir determinados objetivos, é exercida com intuito de influenciar pessoas a trabalharem com entusiasmo e, assim, alcançar metas para o bem geral.

A liderança é um termo que vem sendo moldado e aprimorado ao longo do tempo, designando diferentes abordagens associadas à sua definição e estilos (Versiani et al, 2019). Para melhor entender seu significado e estilos, neste estudo serão utilizadas as seguintes abordagens: Abordagem da personalidade, Abordagem Comportamental, Abordagem Situacional ou Contingencial, Abordagem Transacional, Abordagem Transformacional.

$\mathrm{Na}$ abordagem da personalidade, tem-se como principal teoria a dos traços que define que o líder já tem suas características natas, que já nasce com elas, não podendo ser desenvolvidas. Assim sendo, na teoria dos traços, os líderes possuem traços em sua personalidade, os quais lhes são conferidos um domínio maior de poder diante dos liderados (Cançado, 2010). No decorrer desta teoria, na tentativa de aperfeiçoar características natas dos líderes, surgiram vários autores entre eles, byrma, que aponta três grupos de características: fatores físicos, habilidades inatas e no ultimo grupo temos os itens mais difíceis, como a moderação, introversão, autoconfiança, entre outros fatores (Robbins, 2004). 
Prosseguindo tem-se a abordagem comportamental, a qual se contrapõe a teoria dos traços, entendendo que o comportamento é o foco principal de um líder, sendo que prevalece a ideia de que ela pode ser aprendida, desenvolvida e modificada (Blake \& Mouton, 1978). Essa abordagem elenca os estilos de como deve ser e agir um líder, surgindo neste contexto a ideia de líder autocrático, democrático e liberal (laissez-faire), logo, o líder possui um único comportamento com todos os seus liderados, ocorrendo assim, dificuldade em definir comportamentos eficazes (Robbins, 2004).

Ademais, a abordagem situacional ou contingencial, procura identificar variáveis mais adequadas para cada tipo de liderança (Fiedler, 1981; Hersey, 2004). Nessa abordagem, tem-se a teoria do ciclo vital, que pode ser entendida como a maturidade que o indivíduo tem para se desenvolver profissionalmente. Para esta teoria, a liderança é conduzida por quatro fases: determinar, persuadir, compartilhar e delegar (Vergara, 2016). Sendo assim, considerar a situação e a contingência nos ambientes de negócio é imprescindível para a atuação do líder. Todavia, para se obter a eficácia, o líder deve ser capaz de diagnosticar o ambiente em que se encontra introduzido, distinguindo as necessidades e adaptando suas habilidades (Hersey \& Blanchard, 1980; Bowditch \& Buono, 2002).

Seguindo, a abordagem transacional foi desenvolvida dentro da nova liderança (Carvalho Neto et al, 2012). Nessa abordagem acontece uma troca entre líderes e subordinados, não restrita a natureza econômica, visto que, há um esforço do líder em satisfazer seus subordinados na troca de uma tarefa bem executada (Robbins, 2004). Dessa maneira, é notório que na liderança transacional há uma forte relação entre desempenho e recompensa (Jung \& Avolio, 1999).

Finalizando as abordagens, segue-se com a transformacional, que também faz parte da nova liderança, envolve uma forma de liderança mais próxima dos subordinados, dessa maneira sua atribuição de líder é ser capaz de inspirar, motivar e influenciar seus subordinados sem a expectativa de trocar algo (Tomazela, 2018). Desse modo, liderança transformacional se baseia no interesse coletivo, na qual o líder é capaz de se inspirar na ideia de transformar as crenças e atitudes dos liderados, sendo assim um agente de mudanças (Marchiori et al., 2012; Cavazotte, Moreno \& Bernardo, 2013).

Diante da apresentação das abordagens e teorias acerca da liderança, faz-se necessário apontar uma perspectiva com um olhar mais específico para o tema desse estudo, a liderança feminina. Em vista disto, muitos autores identificam características peculiares no modo de liderar das mulheres, que muitas vezes esses atributos entram em consonância com habilidades desejadas para um bom líder (Loden, 1988; Kets de Vries, 1997; Frankel, 2007). Fisher (2001) ressalta que essas líderes tem o gosto pelo trabalho em rede, negociação, sensibilidade emocional, empatia, capacidade de conciliar diversas tarefas e facilidade de comunicação verbal, que são propícias para a atual sociedade. Segundo Botelho (2008, p. 120), "as mulheres trazem contribuições significativas para o novo modelo de paradigma organizacional, um modelo baseado no conhecimento humano". Adicionalmente, conforme refere Teixeira (2001), as mulheres tendem a exercer um estilo de liderança mais democrático, buscando o encorajamento e a participação ativa de sua equipe, compartilhando do poder e informação pertencente a ela, assim possibilita um crescimento mútuo entre líderes e liderados.

Diante disso, é perceptível que ainda existe uma grande resistência à liderança feminina. Vale ressaltar que a chegada das mulheres em cargos de liderança ainda se encontra vinculadas a expectativas de impedi-las de assumir tal posição (Owen,2013). Essa realidade se explica pelo fato da disseminação de práticas sexistas enraizadas na sociedade, como sendo atreladas a hierarquias organizacionais, onde a mulher é posta como sub-representação em cargos executivos, mesmo tendo formação, experiência, qualificações e adaptações para papéis de liderança (Diehl \& Dzubinski, 2016).

\subsection{Inteligência Emocional}

Inteligência emocional "é a capacidade do indivíduo monitorar os sentimentos e as emoções dos outros e os seus, de discriminá-los e de utilizar essa informação para guiar o próprio pensamento e as ações” (Mayer \& Salovey, 1997, p. 15). Ou 
seja, é conhecer seus sentimentos e moções e conseguir canaliza-los de forma consciente dentro do ambiente em que o indivíduo vive e/ou atua, e com esse esforço promover crescimento emocional e intelectual (Tomazela, 2018).

A inteligência emocional é simplesmente o uso inteligente das emoções - isto é, fazer intencionalmente com que as emoções trabalhem a seu favor, usando-as como uma ajuda para ditar seu comportamento a seu raciocínio de maneira a aperfeiçoar seus resultados (Weisinger, 2001, p. 14).

Para Goleman (2012), “a inteligência emocional é a maior responsável pelo sucesso ou insucesso dos indivíduos, onde a maioria das situações de trabalho são envolvidas por relacionamentos entre as pessoas." A emoção é muito importante e absolutamente necessária para a tomada de boas decisões, pois, se bem administradas, as emoções proporcionam um bom relacionamento e bem-estar organizacional, além de promover outros benefícios como lealdade, comprometimento, aumento da produtividade, otimização na resolução de problemas, mudanças e assim, alcançar o sucesso (Goleman, 2012).

Seguindo essa vertente, é importante ressaltar que "as necessidades físicas e emocionais das pessoas compõem a base para organização. A partir disso, pode-se presumir a importância da inteligência emocional não apenas no ambiente profissional, como também nas demais áreas da vida" (Kwasnicka, 2014. p.43). Com essa visão, evidencia-se que trabalhar as emoções ao seu favor torna-se crucial tanto no ambiente de trabalho como na vida pessoal.

Goleman (1999) caracteriza inteligência emocional em cinco habilidades: (i) autoconhecimento: é a capacidade de reconhecer as próprias emoções, está ligada a autoconsciência (Tomazela, 2018). "As pessoas mais seguras de seus sentimentos são os melhores pilotos da sua vida." (Goleman, 1999); (ii) autocontrole: é a capacidade de lidar com as próprias emoções. O autocontrole está por trás das realizações pessoais que as pessoas alcançam, pois precisam controlar a impulsividade (Tomazela, 2018). Pessoas que possuem autocontrole são mais eficazes e produtivas (Goleman, 1999); (iii) motivação: "é o ato de reunirmos sentimentos como confiança na busca de uma realização ou objetivo" (Tomazela, 2018). Segundo Goleman (1999) quando a pessoa tem a capacidade de se motivar e de se manter motivada ela tem mais êxito em seus feitos; (iv) empatia: é a capacidade de enxergar a experiência pelo olhar do outro (Tomazela, 2018). "as pessoas empáticas estão mais sincronizadas com sutis sinais do mundo externo que indicam o que os outros precisam ou o que querem" (Goleman, 1995); e, por fim, (v) habilidades sociais: um conjunto de capacidades ligadas à interação social que juntas, levam a um "líder natural." (Goleman, 1999).

Segundo um estudo global, divulgado pelo Korn Ferry Hay Group, mulheres se mostram superiores aos homens na hora de gerir as emoções no ambiente de trabalho. As mulheres superam os homens em quase todas as habilidades avaliadas (autoconhecimento, empatia, gestão de conflitos, adaptabilidade e orientação para resultados). O estudo contou com 55 mil profissionais e usou dados coletados entre 2011 e 2015, em 90 países (Pati, 2016).

O estudo usou de base a avaliação de 12 competências emocionais e sociais listadas no Inventário de Competências Emocionais e Sociais (sendo elas: orientação para o resultado, adaptabilidade, coaching e mentoring, gestão de conflito, empatia, autoconhecimento emocional, liderança inspiradora, influência, entendimento organizacional, otimismo, trabalho em equipe e autocontrole emocional); que foi desenvolvido pelo professor Richard E. Boyatzis e daniel goleman, autor do livro "inteligência emocional" (Pati, 2016).

O diferencial maior se deu na competência do autoconhecimento. Os resultados indicam que apenas 9,9\% deles demonstraram autoconhecimento, em comparação a 18,4\% das mulheres avaliadas (Pati, 2016).

"Entre as mulheres, a empatia apareceu $45 \%$ mais frequentemente do que entre os homens. Elas também demonstraram ser mais competentes em relação a coaching, mentoria, capacidade de influência, de liderança inspiradora, gestão de conflito, entendimento organizacional, adaptabilidade, trabalho em equipe e orientação para resultado. Também um pouco mais otimistas do que eles, as mulheres só empatam com os homens em controle emocional" (Pati, 2016). 
Contudo, ainda é evidente que por mais que as mulheres se esforcem e apresentem resultados positivos inegáveis ainda são pouco representadas quando o assunto é liderança. E isso é mais que perceptível quando uma mulher líder é exceção à regra (Tomazela, 2018).

\section{Metodologia}

Para o alcance dos objetivos propostos nesse trabalho, realizou-se uma pesquisa qualitativa. Segundo Silva e Menezes (2001, p. 20) "a pesquisa qualitativa considera que há uma relação dinâmica entre o mundo real e o sujeito, isto é, um vínculo indissociável entre o mundo objetivo e a subjetividade do sujeito". Corroborando Creswell (2007, p.42) diz que, "nessa situação o pesquisador procura estabelecer o significado de um fenômeno a partir dos pontos de vista dos participantes".

De acordo com o desenvolvimento do tema, utilizou-se uma abordagem de caráter descritivo, que, segundo Cervo e Bervian (2002, p. 66) "a pesquisa descritiva observa, registra, analisa e correlaciona fatos ou fenômenos (variáveis) sem manipulá-los". Visto que, "Os fatos são observados, registrados, analisados, classificados e interpretados, sem que o pesquisador interfira neles". (Andrade, 2007, p. 114).

A coleta de dados foi feita por meio da realização de entrevista semiestruturada, essa é uma "técnica em que o investigador se apresenta frente ao investigado e lhe formula perguntas, com o objetivo de obtenção dos dados que interessam à investigação" (Gil, 2008, p.128). Nesse contexto, sendo um instrumento fundamental para mapear práticas, crenças, valores e sistemas sociais específicos, em que os entrevistados estão inseridos (Duarte, 2004). As entrevistas foram realizadas por meio da plataforma Google Meet, na qual foram gravadas e, posteriormente, transcritas, com média de 15 minutos, por entrevistada.

As entrevistadas, para a coleta de dados, foram mulheres que exercem ou já exerceram papel de liderança em suas respectivas áreas de trabalho, bem como no Assentamento Marrecas. O critério de escolha foi a acessibilidade e disponibilidade das mesmas. Dentre as 15 (quinze) mulheres que são líderes, atualmente, no assentamento, 5 (cinco) mostraram-se disponíveis para a pesquisa e, foram representadas nesta pesquisa, como; E1, E2, E3, E4 e E5. O Quadro 01 demostra o perfil descritivo das entrevistadas.

Quadro 1- Perfil descritivo das entrevistadas.

\begin{tabular}{|c|c|c|c|c|c|}
\hline Descrição & E1 & E2 & E3 & E4 & E5 \\
\hline Idade & 31 anos & 37 anos & 49 anos & 32 anos & 45 anos \\
\hline Estado Civil & Solteira & Solteira & Casada & Solteira & Casada \\
\hline Área de atuação & $\begin{array}{c}\text { Educação/ } \\
\text { Professora } \\
\text { Ex-Dirigente } \\
\text { Estadual e } \\
\text { comunitária }\end{array}$ & $\begin{array}{c}\text { Gestão } \\
\text { Escolar/Coord. } \\
\text { Pedag. } \\
\text { Ex- } \\
\text { Coordenadora } \\
\text { comunitária }\end{array}$ & $\begin{array}{c}\text { Gestão } \\
\text { Coolar/Diretora } \\
\text { comunitária }\end{array}$ & $\begin{array}{c}\text { Gescolar/Coord. } \\
\text { Pedag. } \\
\text { Ex-Dirigente } \\
\text { comunitária }\end{array}$ & $\begin{array}{c}\text { Educação/ } \\
\text { Professora } \\
\text { dos direitos da } \\
\text { mulher de SJ-PI }\end{array}$ \\
\hline $\begin{array}{c}\text { Anos de } \\
\text { atuação }\end{array}$ & 8 anos & 8 anos & 15 anos & 10 anos & 12 anos \\
\hline
\end{tabular}

Fonte: Autoras (2021).

O instrumento utilizado, como método de coleta de dados, foi um roteiro de entrevista estruturado contendo 5 (cinco) questões com teor de resposta discursiva. A primeira questão foi para entender qual é a percepção de liderança das entrevistadas; a segunda, para analisar o perfil de liderança das participantes da pesquisa, conforme Tomazela (2018); a terceira questão foi para identificar quais habilidades da inteligência emocional, abordado por Goleman (1999) são inerentes a formação das entrevistadas; na sequência, a quarta questão pede para que as entrevistadas mencionem quais habilidades de 
inteligência emocional se destacam na liderança feminina delas; e, por fim, a quinta questão foi para saber quais dificuldades as entrevistadas enfrentam e/ou enfrentaram em sua trajetória como líder em uma comunidade de área rural.

\section{Análise e Discussão dos Resultados}

Tendo apresentado a fundamentação teórica e os passos metodológicos da pesquisa, nessa seção, se fará a análise dos dados e os resultados obtidos por meio das respostas apresentadas.

\subsection{O Assentamento Marrecas}

O Assentamento Marrecas surgiu juntamente com o MST (Movimento dos Trabalhadores Rurais Sem Terra) no Piauí, sendo a primeira ocupação de terra realizada no Estado pelo movimento. É resultado de uma luta pela conquista do direito à terra, e seu percurso histórico de luta do período se deu através dos trabalhos de base, e com a participação de 120 famílias, envolvendo cidades como: Paulistana, Pio IX, Simões, Itainópolis, Padre Marcos, Oeiras e Dom Expedito Lopes, etc. No dia 10 de junho de 1989, aconteceu a $1^{a}$ ocupação de terra organizada pelo MST no Estado do Piauí. (Vitor, 2016)

Atualmente, o assentamento Marrecas tem 31 anos de vivência, com 330 famílias, numa área de 10.500 hectares, localizado ao lado da PI 141, que liga São João do Piauí a Brejo do Piauí, distante 35 km da cidade São João do Piauí e 499 km da Capital Teresina. A área total conquistada fica no semiárido do Sul do Piauí, com parte da vegetação carqueja caatinga, com um subsolo muito rico em água. Sendo assim, uma potencialidade da região de São João do Piauí, em termos econômicos, educacionais e culturais. (Vitor, 2016)

\subsection{As Entrevistas}

A primeira questão propõe que as entrevistadas apresentem características de liderança dentro da sua perspectiva de trabalho. Observando as respostas, constatou-se que as entrevistadas têm um bom entendimento subjetivo em relação ao conceito de liderança, alinhando o discurso das falas à teoria defendida por Bateman e Snell (1998) sobre o tema.

"Bom, para mim um Lider é quem busca coisas novas, quem vai atrás e quem enfrenta as questões, né? as questões da vida, seja no trabalho, seja na sua casa, onde você atuar, né? enquanto mulher nesse caso”. (E1).

"Na minha reflexão é que deve ser uma pessoa que busca uma harmonia entre todos, ou seja, fazer essa mediação de forma organizada e participativa" (E2).

"É uma função desafiadora né, por exemplo precisamos ter disposição e articulação... e buscando sempre está aberto ao diálogo, buscando opiniões" (E3).

"Um bom líder tem que entender os problemas do seu grupo e resolver da melhor forma possivel, tem que ter empatia com aqueles com quem trabalha" (E4).

"Liderar é respeitar a individualidade de cada um, trabalhar conjuntamente com todos, de forma colaborativa em busca de obtermos objetivos em comum" (E5).

Reforçam, por certo, a opinião de Macedo, et al (2011) que afirmam que um bom líder é aquele que é capaz de lidar com as frequentes mudanças e incertezas, estimulando e orientando seus seguidores na busca de melhores resultados.

A segunda questão, foi extraída do questionário de Tomazela (2018), elaborado para analisar o perfil de abordagem de liderança das participantes da pesquisa. Tem-se, portanto, que:

"Eu resolvi escolher a letra E né, o líder deve motivar os seus liderados ter uma atitude próxima dos seus profissionais, porém não promete nada em troca, porque eu acho que o líder deve motivar né, ter uma proximidade" (E1). 
"Eu escolhi a letra E, na minha concepção deve haver sempre a motivação e conduzir a todos como bons profissionais, saber inspira-los e sempre orientando toda a equipe para um bom trabalho, porque assim todo ambiente de trabalho precisar haver sempre a motivação para que todos possam desenvolver sua tarefa da melhor forma” (E2).

"O item que eu mais me identifico é o lider deve motivar seus liderados, letra E, pois através da motivação, no meu caso como gestora da escola, toda equipe escolar precisa estar motivada e participando do processo” (E3).

"Escolho a letra B, porque devemos tratar todos da mesma forma, independente de sua função enquanto profissional, com respeito e colaboração, para que todos se sintam motivados a participarem e executarem suas funções" (E5).

"Letra C. A liderança depende da maturidade dos liderados, ele tem que conhecer cada um para poder agir de acordo com a experiência apresentada sempre tem aqueles liderados que tem uma promoção diferente que se adéqua mais um trabalho do que o outro, então o bom líder tem que agir de modo diferente com essas liderados" (E4).

As entrevistadas (E1), (E2) e (E3) se identificaram mais com o quinto item que corresponde a abordagem transformacional que tem por objetivo inspirar os liderados (Tomazela, 2018). Visto que, a liderança transformacional se baseia no interesse coletivo, na qual o líder e capaz de motivar e de se inspirar na ideia de transformar as crenças e atitudes dos liderados, agindo como um agente de mudanças (Marchiori et al., 2012; Cavazotte, Moreno \& Bernardo, 2013).

A entrevistada (E4) optou pelo terceiro item que foi baseado na abordagem situacional ou contingencial. Nessa abordagem o líder deve ser capaz de reconhecer a diferença entre seus liderados, diagnosticando o ambiente em que se encontra introduzindo, e adaptar suas habilidades as necessidades encontradas (Hersey \& Blanchard, 1980; Bowditch \& Buono, 2002). E a entrevistada (E5) se identificou com a abordagem comportamental, na qual o líder deve ter o mesmo comportamento com todos os seus liderados (Blake \& Mouton, 1978).

A terceira questão é sobre as habilidades da inteligência emocional, abordado por Goleman (1999). Nesse ponto, as participantes destacaram quais habilidades são inerentes ao seu ser.

"Eu listei algumas aqui em que eu mais me identifico, o autoconhecimento porque eu reconheço minhas emoções né, mesmo que às vezes eu seja muito sensível... então acho que esse autoconhecimento eu vejo em mim né, sou muito questionadora sempre pergunto porque que as coisas têm que ser assim né, e não de outro jeito, e quero sempre o melhor né,... é motivação também é um que eu tenho né, eu procuro sempre motivar meus alunos, o povo né... Outro é a empatia eu tenho em mim, eu tento né me colocar sempre no lugar do outro sempre procuro desenvolver esse exercício... E ainda sobre as habilidades eu acho que outro que eu me identifico são as habilidades sociais"(E1).

"Nessa questão eu olhei para a habilidade social, que é uma ferramenta que nos ajuda a interagir com as pessoas ao nosso redor. Viver em comunidade nos faz expressar esse desejo de organização de opiniões, por isso que eu olhei muito perto a questão da habilidade social. " (E2).

"Acredito que todas as 5 habilidades, elas estão assim interligadas nesse processo, principalmente no processo da gestão, quando a gente está à frente né. Nesse momento acredito na empatia, e quanto essa habilidade a empatia eu vejo a necessidade de escutar de ser atencioso com outro procurar, compreender a outras formas de comportamento $n e ́ ”(E 3)$.

"Das habilidades da Inteligência Emocional listadas, escolho o autoconhecimento que é a capacidade de conhecer as próprias emoções e ligada alta consciência... a empatia também que é a capacidade chegar a experiência pelo olhar do outro, eu sempre estava à frente conversando com as pessoas sobre as questões e olhando para o olhar do outro em relação a liderança." (E4).

“Eu me identifico mais com a motivação e a empatia na minha perspectiva de trabalho” (E5).

Analisando os resultados, a habilidade mais mencionada é a empatia, que segundo Goleman (1995), as pessoas empáticas são mais sincronizadas com o mundo externo, conseguindo assim identificar o que os outros precisam ou querem. Reforçando esse resultado o estudo divulgado pelo o Korn Ferry Hay Group, entre as mulheres, a empatia apareceu $45 \%$ mais frequente que os homens. Em segundo lugar, destacou-se o autoconhecimento, dado que "as pessoas mais seguras de seus 
sentimentos são os melhores pilotos da sua vida." (Goleman, 1999). Entre as respostas destacaram-se, também, habilidades sociais e motivação.

A quarta questão solicita para que as entrevistadas mencionem quais habilidades de inteligência emocional se destacam na liderança feminina delas. "Penso que a liderança feminina precisa ter uma relação bem íntima, né e forte com essas habilidades emocionais,
porque a sociedade é muito machista... todas podemos ter né, a gente tendo por exemplo, autoconhecimento, o
autocontrole, a motivação empatia e habilidade sociais, a gente pode continuar né, ajudando e liderando a nossa
Comunidade a nossa sociedade e até o país, e porque quando eu estava falando a sociedade ainda é machista e a
mulher tida como uma coisa que tem que ficar em casa, não pode ser líder, não pode estar a frente de nada, então a
gente tenta sim quebrar essas coisas... Porque a empatia eu vejo que é uma coisa que nós mulheres já temos, isso é
uma coisa assim nata da mulher"(E1).

"Olhando para essas habilidades autocontrole, motivação e empatia elas estão bem ligadas ao próprio amadurecimento emocional né, e principalmente a questão do autocontrole... Essa questão da empatia que é a oportunidade do próprio exercício de se colocar no lugar do outro e aí olhando mais para essa questão da liderança feminina a gente demostrar muito essa questão da generosidade do afeto um com outro" (E2).

"No meu entender acredito que todas as suas 5 habilidades. Dentre elas se fosse pra escolher e ficar uma só ficaria com a empatia, porque a liderança uma das funções muito importante que vejo é essa questão de saber ouvir o outro, se colocar no lugar do outro para poder se planejar, não vale só a minha opinião, mas a opinião do outro também é importante, e a gente tem que nesse processo tem que envolver os outros" (E3).

"Podemos associar a motivação, pois devemos estar motivados e também motivando os outros para participarem das ações. Outra habilidade seria a empatia, estarmos enxergando as dificuldades do outro, de forma a contribuir com seu desenvolvimento enquanto ser humano" (E5).

"Questão de acreditar em si mesmo se auto entender de motivar a entender que cada uma pode ser quem quiser ser ter um futuro melhor e ser a pessoa que possa se identificar como dona de si mesmo. (Autoconhecimento, motivação)" (E4).

Para as entrevistadas (E1), (E2) e (E3), que se identificaram com a abordagem transformacional, percebeu-se que as habilidades escolhidas foram empatia, autocontrole e motivação. Nesse aspecto, as habilidades destacadas tem uma forte ligação com essa abordagem, pois o líder transformacional, como citado anteriormente, tem que ser capaz de motivar, inspirar e agir como agente de mudança. Em consonância, Fisher (2001) ressalta que, mulheres líderes tem o gosto pelo trabalho em rede, negociação, sensibilidade emocional, empatia, capacidade de conciliar diversas tarefas e facilidade de comunicação verbal.

A entrevistada (E4) que se identificou com o perfil de líder situacional (ou contingencial) destacou as habilidades de autoconhecimento e motivação. As habilidades citadas pela entrevistada entram em pleno acordo com a proposta da abordagem, pois, nessa, o líder precisa reconhecer a diferença entre seus liderados, diagnosticar o ambiente em que se encontra inserido, e adaptar suas habilidades as necessidades encontradas.

Por sua vez, a entrevistada (E5) que se identificou com a abordagem comportamental destacou motivação e empatia como habilidades da liderança feminina. Nessa abordagem são elencados os estilos de como deve ser e agir um líder, surgindo assim à ideia de líder autocrático, democrático e liberal. Teixeira (2001) diz que, as mulheres tendem a exercer um estilo de liderança mais democrático, buscando o encorajamento e a participação ativa de sua equipe.

Por fim, a quinta questão indaga sobre quais dificuldades as entrevistadas enfrentam e/ou enfrentaram em sua trajetória como líder em uma comunidade de área rural.

"Na minha trajetória marca a própria insegurança, o medo, em alguns processos dentro da comunidade, talvez por mulher ainda somos vistas com mau olhares, embora temos dado passos importantes. E dentro dessa trajetória está a luta das mulheres, onde é fundamental ampliar nossa capacidade de argumentação nos trabalhos, nas mudanças de pensamentos e comportamentos construindo assim uma nova perspectiva de vida e organização. Então dentro dessa 
trajetória marca a própria vivência né, como viver em coletividade dentro de uma comunidade, porque as dificuldades vêm, mas o que marca é a luta, né o próprio caminhar” (E2).

"tem várias dificuldades, algumas são a dificuldade de articulação com os demais membros... Outra dificuldade também é em conciliar as funções enquanto mulher, no trabalho em casa, enquanto família, filhos né. Quantas vezes não ser entendida algumas vezes por conta de ter que deixar a casa e ir trabalhar fora né para, buscar melhor condição de vida" (E3).

"então assim uma das dificuldades que eu encontrei nessa trajetória, era às vezes, é uma era falta de experiência né, que eu não tinha muito mas eu tinha muita vontade e outras pessoas não queriam assumir, mas às vezes eu sentia que algumas pessoas não confiavam no meu trabalho por eu ser jovem e tal... eu senti um pouco de dificuldade no início, não vou negar né, como falar com pessoas mais velhas que os coordenadores de núcleo a maioria eram mais velhos que eu, então é, como convencê-los a fazer alguma coisa” (E1).

“Encontrei algumas dificuldades em relação a comunicação”(E4).

“As dificuldades não são poucas, mas um dos problemas que vivencio é a mobilização das pessoas para participarem de reuniões, eventos, devido as mesmas às vezes não acreditarem mais nas discussões” (E5).

Os pontos levantados pelas entrevistadas foram: a própria insegurança, o medo, a dificuldade de articulação e comunicação, na qual, por serem mulheres, ainda são vistas com maus olhares, dificuldade em conciliar as funções enquanto mulher, no trabalho e em casa. Ser julgada por ter que deixar a casa e ir trabalhar fora, em busca de melhor condição de vida, o que é uma realidade enfrentada por muitas mulheres de comunidades rurais.

Corroborando, o setor de gênero do MST (2017) traz que, mesmo com o progresso da participação feminina dentro dos assentamentos, as mulheres continuam sendo desvalorizadas, pois ainda se tem um pensamento de que as mulheres têm ou trazem obrigações pessoais e intrasferíveis que as impedem de participar da mesma forma que os homens.

\section{Considerações Finais}

O estudo teve como enfoque compreender como a liderança e a inteligência emocional promovem a formação das líderes rurais femininas do Assentamento Marrecas, em São João do Piauí-PI. Dessa feita, realizou-se uma pesquisa qualitativa-descritiva com 5 (cinco) mulheres líderes do assentamento, assim, evidenciou-se, por meio dos resultados, que traços da liderança, transformacional, situacional (ou contingencial) e comportamental; e aspectos da inteligência emocional como, empatia, autocontrole, motivação e autoconhecimento estão no seio da formação da liderança feminina das entrevistadas no estudo. Por certo, essas características estão promovendo, favoravelmente, a construção e formação da liderança feminina da comunidade.

Especificadamente, o primeiro objetivo foi alcançado, identificar os perfis de liderança dessas mulheres; a pesquisa mostrou que as participantes ficaram divididas entre três perfis de abordagem; o transformacional, o situacional e o comportamental. Traçando o perfil das líderes a abordagem transformacional foi mais mencionada entre elas, visto que essa abordagem se baseia no interesse coletivo, na qual o líder é capaz de motivar e de se inspirar na ideia de transformação. Com o contexto de comunidade rural, o líder transformacional pode trazer mais benefícios para essa realidade.

Segundo, levantar as habilidades de inteligência emocional em suas condutas como líderes; de acordo com os dados da entrevista, foi possível concluir que elas reconheceram a importância das 5 (cinco) habilidades para o sucesso de um líder e, o item relacionado a empatia, foi o que obteve uma maior variação no nível de resposta, seguida por autocontrole, motivação e autoconhecimento.

E, por fim, identificar possíveis dificuldades na formação da liderança feminina dentro da comunidade que atuam. Os pontos levantados pelas entrevistadas foram; a própria insegurança, o medo, a dificuldade de articulação e comunicação, na 
qual, por serem mulheres, ainda são vistas com maus olhares. E, ainda, pela dificuldade em conciliar as funções enquanto mulher, no trabalho e em casa, e ser julgada por ter que deixar a casa e ir trabalhar fora.

Evidencia-se, por certo, a importância da presença feminina dentro dessas comunidades e, mesmo com todas as dificuldades socialmente atreladas a elas, percebe-se que elas acendem cada vez mais a cargos de alta liderança. Não se pode negar, que a presença feminina nesses espaços de liderança acaba sendo uma forma de representatividade, rompendo barreiras culturais ultrapassadas e fazendo com que a sociedade desmonte o conceito retrogrado de inferioridade feminina. Fato, é que essas mulheres inspiram e são referência para outras mulheres. Isso mostra um diferencial importante para a comunidade, atraindo talentos femininos para ocupar esses espaços de liderança.

A limitação desse estudo está relacionada a dificuldade de se reunir um número maior de entrevistadas. E, como recomendações para futuras pesquisas, sugerem-se a continuidade do estudo sobre liderança feminina e inteligência emocional em outros contextos, sejam rurais ou urbanos, ampliando, assim, os sujeitos/amostra, bem como a realização de uma pesquisa quantitativa da possível relação entre liderança e inteligência emocional na formação de lideranças, independentemente do gênero, campo de atuação, escolaridade, dentre outros.

\section{Referências}

Andrade. M. M. (2007) Introdução À Metodologia do Trabalho Científico, (8a ed.), revista Atlas.

Blake, R. \& Mouton, J. S. (1978) O grid gerencial. (3a ed.), revista Pioneira.

Botelho, L. L. R. (2008) Ascensão profissional de executivas em empresas baseadas no conhecimento. 2008.161 f. Dissertação (Mestrado em Engenharia) Programa de Pós-Graduação em Engenharia e Gestão do Conhecimento, Universidade Federal de Santa Catarina, Florianópolis, SC.

Bateman, T. S. \& Snell, S. A. (1998) Administração: construindo vantagem competitiva. revista Atlas.

Bowditch, J. \& Buono, A. (2002) Elementos do comportamento organizacional. revista Pioneira Thomson.

Cançado, V. L. (2010) Desenvolvimento de competências de liderança global: Líder à brasileira? Inn: Liderança: entre a tradição, a modernidade e a pósmodernidade. Rio de Janeiro: Elsevier. 1(5), 95-116.

Carvalho Neto, A., Tanure, B., Santos, C. M. M. \& Lima, G. S. (2012) Executivos Brasileiros: na contramão do perfil deificado da liderança transformacional. Revista Ciência da Administração. 14(32) 35-49.

Cavazotte, F., Moreno Jr. V. \& Bernardo, J. (2013) Transformational leaders and work performance: the mediating roles of identification and self-efficacy. Brazilian Administration Review, 10(4), 490-512.

Cervo, A. L. \& Bervian, P. A. (2002) Metodologia Científica, (5a ed.), revista Pearson Prentic Hall.

Coletivo Nacional de Mulheres do MST. (1998) Compreender e construir novas relações de gênero. revista MST.

Creswell, J. W. (2007) Projeto de pesquisa: métodos qualitativo, quantitativo e misto. revista Artmed.

Diehl, A.B. \& Dzubinski, L.M. (2016) Making the invisible visible: a cross-sector analysis of gender-based leadership barriers, Human Resource Development Quarterly, 27 (2), 181- 206. Dileo, I.

Duarte, R. (2004) Entrevistas em pesquisas qualitativas. Educar, 24, 213-225.

Fiedler, F. E. (1981) Liderança e administração eficaz. Revista Pioneira.

Fischer, H. (2001) O primeiro sexo - como as mulheres estão a mudar o mundo. revista Presença.

Frankel, L. P. (2007) Mulheres Lideram Melhor que Homens. (85a ed.), revista Editora Gente.

Gil, A. C. (2008) Métodos e técnicas de pesquisa social. (6 ed.), revista Atlas.

Goleman, D. (1995) Inteligência Emocional. Revista Objetiva.

Goleman, D. (2012) Inteligência emocional. Revista Objetiva.

Goleman, D. (2014) Liderança: A inteligência emocional na formação de líderes de sucesso. Editora: Objetiva.

Goleman, D. (1999) Trabalhando com a inteligência emocional. Revista Objetiva.

Goleman, D. (1998) What makes a leader? Harvard Business Review, 76 (6), 93-102. 
Research, Society and Development, v. 10, n. 8, e8810816618, 2021

(CC BY 4.0) | ISSN 2525-3409 | DOI: http://dx.doi.org/10.33448/rsd-v10i8.16618

Hersey, P. (2004) The Situational Leader.

Hersey, P. \& Blanchard, K., H. (1974) Psicologia para Administradores de empresas. revista EPU.

Hersey, P. \& Blanchard, K. H. (1986) Psicologia para administradores: a teoria e as técnicas da liderança situacional. revista EPU.

Hunter, J. C. (2006) Como se tornar um líder servidor: os princípios de liderança de o monge e o executivo. (3a ed.), revista Sextante.

Jung, D. I. \& Avolio, B. J. (1999) Effects of Leadership Style and Followers' Cultural Orientation on Performance in Group and Individual Task Conditions. The Academy of Management Journal. 42(2), 208-218.

Kets V. \& Manfred F. R. (1997) Liderança na empresa: como comportamento dos líderes afeta a cultura interna. Editora Atlas.

Kwasnicka, E. L. (2005) Introdução a administração. Revista Atlas, S.A.

Loden, M. (1988) Liderança feminina: como ter sucesso nos negócios sendo você mesma. Editora Bandeirante.

Latu, I. M. et al. (2013) Successful female leaders empower women's behavior in leadership tasks. Journal of Experimental Social Psychology.

Macedo, I. I., Rodrigues, D. F., Johann, M. E. P. \& Cunha, N. M. M. (2011) Aspectos comportamentais da gestão de pessoas. Série gestão empresarial. Revista $F G V$

Marchiori, M., Wilma P. T. V., Fabiana R. S., Pinto R. S. \& Fonseca R. K. A. (2012) A liderança transformacional e discursiva revelada ou desvelada? Um estudo empírico no campo da Indústria Gráfica. In: EnAnpad, 34.

Mayer, J. D. \& Salovey, P. (1997) What is emotional intelligence? In: Salovey, P. \& Sluyter, D. J. (Orgs.). Emotional development and emotional intelligence: implications for educators. Basic Books, p. 3-31.

Movimento dos Trabalhadores Rurais Sem Terra. MST (2017) Caderno de formação setor de gênero: a conspiração dos gêneros elementos para o trabalho de base.

Owen, C. (2013) Gendered communication and public safety: women, men and incident management, Australian Journal of Emergency Management, 28 (2), $3-10$.

Pati, C. (2016) Mulheres superam homens em 11 de 12 habilidades emocionais. Revista Exame. < https://exame.com/carreira/mulheres-superam-homens-em11-de-12-habilidades-emocionais/>.

Pinto, Z. (2015) Sem medo de ser mulher. Coordenação Geral: Movimento dos Trabalhadores Rurais Sem Terra. Estúdios: Estúdio P. Rede Cultural da Terra; Estúdio Rio Abaixo; Estúdio MCA e Estúdio CPMídias. Disco sonoro.

Robbins, S. P. (2004) Comportamiento Organizacional. (10a ed.), revista Pearson Education.

Rodrigues, S. C. \& Silva, G. R. (2015) A liderança feminina no mercado de trabalho. Revista digital de administração FACIPLAC. 1 (4). Gama-DF.

Santos, F. C. S. (2011) Inteligência Emocional.. Ed. Clube de Autores.

Silva, E. L \& Menezes, E. M. (2001) Metodologia da pesquisa e elaboração de dissertação. 2 ed. Florianópolis: Laboratório de Ensino a Distância da UFSC.

Teixeira, S. (2001) A gestão das organizações. Mc Graw-Hill.

Tonani, A. V. (2011) Gestão Feminina - Um diferencial de liderança mito ou nova realidade. Agosto. VII Congresso Nacional de Excelência em Gestão.

Tomazela, C. V. (2018) Relatos sobre inteligência emocional por mulheres líderes. Dissertação (Mestrado em Gestão do Conhecimento e Tecnologia da Informação) - Universidade Católica de Brasília, Brasília.

Vergara, S. C. (2016) Gestão de pessoas. (16a ed.), revista Atlas.

Versiani, F., Caeiro, M., Martins, M. \& NETO, A. C. (2019) Características de liderança das mulheres empreendedoras: Um estudo de caso no setor de serviços. Revista de Administração da UNIMEP. 17(1),

Weisinger, H. (2001) Inteligência Emocional no trabalho: como aplicar os conceitos revolucionários da I.E. nas suas relações profissionais, reduzindo o estresse, aumentando sua satisfação, eficiência e competitividade. Revista Objetiva. 